\title{
Gerenciamento de Riscos: Case de sucesso em Hemodinâmica
}

Autores: Juliana Silveira Rodrigues Gonçalo; Fabiana Maria Scire, Veridiana Cordaro; José Antonio Maluf, Monica Morgese Alves.

\section{Sobre a instituição}

A BP - A Beneficência Portuguesa de São Paulo é um polo de saúde composto por 4 hospitais e 3 outros serviços de saúde e de educação e pesquisa. Fundada em 1859, a BP possui 8.000 colaboradores, 4.500 médicos cadastrados e oferece serviços de saúde privados e para clientes encaminhados via regulação pelo Sistema Único de Saúde (SUS).

\section{Introdução}

O comitê de gerenciamento de riscos (GR) em conjunto com a liderança da hemodinâmica identificou reincidência de complicações nos pacientes submetidos a procedimentos de cateterismo cardíaco e/ou angioplastia, que embora previstos em literatura podem ter objeto de ações para diminuição dos riscos.

No ano de 2016 foram notificados 46 eventos adversos (EA) na hemodinâmica que após serem analisados foram identificados 21 com oportunidades de melhoria (45\%), sendo que 7 atingiram de forma grave os pacientes.

\section{Objetivo}

Estabelecer preventivamente planos de melhoria no processo de prevenção de incêndio no ambiente hospitalar, após a utilização da ferramenta FMEA.

\section{Metodologia}

Na busca contínua de melhorias na qualidade e segurança do paciente a equipe da hemodinâmica e GR se dedicaram para estruturação de ações com foco na mitigação dos riscos assistências, identificados nas análises de causa raiz. Foi estruturado um comitê com todas equipes médicas atuantes no serviço, além de representantes da equipe multidisciplinar com encontros periódicos, onde cada membro era responsável por apresentar um caso e promover a discussão com foco em geração de aprendizado; foi elaborado um protocolo com diretrizes clínicas amplamente discutidas para cada complicação prevista em cada fase dos procedimentos; revisado os papéis e responsabilidades de cada membro da equipe multidisciplinar; estruturado treinamento periódico para equipe assistencial; revisado e fortalecido os SLAs com os serviços de apoio para prontidão nos atendimentos; revisado os critérios de admissão e alta no serviço; fortalecido o papel da equipe médica e enfermagem da triagem como membros determinantes para as barreiras de segurança relacionados a preparo e condições clínicas para realização dos procedimentos; implantado o time out sob liderança da enfermagem para a completude dos procedimentos; reestruturado os indicadores e reuniões de análises críticas multidisciplinares mensais para discussão dos resultados com reporte a alta liderança.

\section{Resultados}

As ações foram implantadas no primeiro semestre de 2017 e no período de julho de 2017 a outubro de 2018 foram notificados 22 EA, dos quais 4 haviam oportunidades de melhoria e 0 com danos graves aos pacientes.

\section{Conclusão}

Desta forma, concluímos que houve efetividade no plano de trabalho executado e que o fator determinante para o sucesso foi o engajamento de todos os membros da equipe multidisciplinar e as áreas de apoio incluindo a alta liderança. 